\title{
The association between cadmium exposure and chronic airflow limitation and emphysema: the Swedish CArdioPulmonary Biolmage Study (SCAPIS pilot)
}

\author{
To the Editor:
}

Cadmium is a metal that is widely spread in the environment and human populations are exposed to it through food, mainly grains and vegetables. The tobacco plants accumulate cadmium, and tobacco smokers accumulate the cadmium in tobacco smoke, which is absorbed in the lungs [1]. Occupational exposure to cadmium has been linked to the development of emphysema and impaired lung function [2,3]. Increased levels of blood cadmium (B-Cd) or urinary cadmium are associated with lower lung function, and it has been suggested that cadmium, in the low-dose interval, is a risk factor for impaired lung function [1, 4].

The aim of this study was to examine whether cadmium exposure in the low-dose interval was associated with increased prevalence of emphysema and impaired pulmonary function.

The study population comprised subjects aged 50-64 years randomly selected from the population in Gothenburg $(n=1111)$ [5]. All subjects answered a questionnaire and performed dynamic spirometry including forced expiratory volume in $1 \mathrm{~s}\left(\mathrm{FEV}_{1}\right)$ and forced vital capacity (FVC). From diffusing capacity measurements for carbon monoxide, diffusing capacity $\left(D_{\mathrm{LCO}}\right)$ and transfer coefficient $\left(K_{\mathrm{CO}}\right)$ of the lung for carbon monoxide were obtained [6]. A Jaeger Master Screen pulmonary function testing (Vyaire Medical, Mettawa, IL, USA) was used for all measurements. Residual volume (RV) and total lung capacity (TLC) were measured using a body box. All procedures were performed after inhalation of $400 \mu \mathrm{g}$ of salbutamol and according to American Thoracic Society/European Respiratory Society standards, as previously described [5]. Predicted values and lower limits of normal (LLN) were based on published equations [7-10]. Predicted values $\left(\mathrm{FEV}_{1}\right.$ and $\left.\mathrm{FVC}\right)$ were based on recently developed equations from same source population [7]. Cadmium (B-Cd) was analysed in whole blood, as described previously [11]. The pulmonary computed tomography (CT) investigations were performed and assessed according to international guidelines [12].

Chronic airflow limitation according to Global Initiative for Obstructive Lung Disease $\left(\mathrm{CAL}_{\mathrm{GOLD}}\right)$ was defined as an $\mathrm{FEV}_{1} / \mathrm{FVC}$ ratio $<0.7$. Chronic airflow limitation $\left(\mathrm{CAL}_{\mathrm{LLN}}\right)$ was defined as $\mathrm{FEV}_{1} / \mathrm{FVC}$ ratio below the LLN. Emphysema was defined as having at least mild emphysema in any zone of the lungs. Centrilobular emphysema was defined as having centrilobular emphysema in any zone of the lungs. Smoking was categorised as current smoker, former smoker or never-smoker. Pack-years (cumulative tobacco exposure) were calculated for all participants with a history of smoking. Never-smokers were assigned 0 (zero) pack-years. Socioeconomic status was defined according to the highest level of education achieved. Body mass index was defined as measured weight $/ h_{\text {height }}^{2}\left(\mathrm{~kg} \cdot \mathrm{m}^{-2}\right)$. Occupational exposure to vapour, gas, dust or fumes was based on an affirmative answer to the item "Have you ever been exposed to vapour, gas, dust or fumes at your workplace?". B-Cd was classified in quartiles: $<0.16 \mu \mathrm{g} \cdot \mathrm{L}^{-1} ; 0.16-$ $<0.23 \mu \mathrm{g} \cdot \mathrm{L}^{-1} ; 0.23-<0.39 \mu \mathrm{g} \cdot \mathrm{L}^{-1}$; and $0.39-3.63 \mu \mathrm{g} \cdot \mathrm{L}^{-1}$.

@ERSpublications

In this general population sample with detailed control for smoking habits there is an association between blood cadmium and emphysema based on lung computed tomography http://bit.ly/2K9S39J

Cite this article as: Torén $\mathrm{K}$, Olin $\mathrm{A}-\mathrm{C}$, Johnsson $\AA$, et al. The association between cadmium exposure and chronic airflow limitation and emphysema: the Swedish CArdioPulmonary BioImage Study (SCAPIS pilot). Eur Respir J 2019; 54: 1900960 [https://doi.org/10.1183/13993003.00960-2019]. 
Correlations (Spearman, $\mathrm{r}_{\mathrm{s}}$ ) were analysed between B-Cd and pack-years, and $\mathrm{FEV}_{1}, \mathrm{FEV}_{1} / \mathrm{FVC}_{\text {ratio, TLC, }}$ $\mathrm{RV}, D_{\mathrm{LCO}}$ and $K_{\mathrm{CO}}$. Associations between B-Cd quartiles and emphysema, centrilobular emphysema and CAL were analysed using multiple logistic regression models and associations between B-Cd quartiles and continuous pulmonary function variables using multiple linear regression models. All models were adjusted for age, socioeconomic status, occupational exposure and smoking. In model 1 the smoking adjustments included current smoking and former smoking versus never-smoking, and in model 2 the smoking adjustment included pack-years. All calculations were performed using SAS (version 9.2; SAS Institute, Cary, NC, USA). p-values $<0.05$ were considered significant.

The study was approved by the regional committee of ethics in Umeå, 2010/228-31, and all included subjects gave their written consent to participate in the study.

Out of the 1111 subjects, complete data on lung CT, lung function and B-Cd was obtained for 741 individuals (381 males and 360 females), mean age 57.1 years. From the lowest to the highest B-Cd quartile the mean age was 56.4, 57.1, 57.7 and 57.0 years, respectively. The study population consisted of 45.3\% ( $n=336)$ never-smokers and $17.4 \%$ current smokers $(n=129)$, with mean 16.7 pack-years for former smokers and mean 20.5 pack-years for current smokers. From the lowest to the highest B-Cd quartile the means were 3.3, 5.4, 7.9 and 18.9 pack-years, respectively. Among all individuals the mean B-Cd concentration was $0.38 \mu \mathrm{g} \cdot \mathrm{L}^{-1}$, median $0.24 \mu \mathrm{g} \cdot \mathrm{L}^{-1}$. Never-smokers had significantly lower B-Cd (mean $0.22 \mu \mathrm{g} \cdot \mathrm{L}^{-1}$, median $0.19 \mu \mathrm{g} \cdot \mathrm{L}^{-1}$ ), compared with current smokers (mean $1.02 \mu \mathrm{g} \cdot \mathrm{L}^{-1}$, median $0.85 \mu \mathrm{g} \cdot \mathrm{L}^{-1}$ ). The correlation $\left(r_{s}\right)$ between B-Cd and pack-years was $0.48(\mathrm{p}<0.0001)$; among individuals with emphysema it was $0.42(\mathrm{p}<0.001)$; and among those with no emphysema it was $0.37(\mathrm{p}<0.001)$. For all individuals, there were significant negative correlations between $\mathrm{B}-\mathrm{Cd}$ and $\mathrm{FEV}_{1} / \mathrm{FVC}$ ratio $\left(\mathrm{r}_{\mathrm{s}}=-0.08\right)$, TLC $\left(\mathrm{r}_{\mathrm{s}}=-0.25\right), D_{\mathrm{LCO}}\left(\mathrm{r}_{\mathrm{s}}=-0.39\right)$ and $K_{\mathrm{CO}}\left(\mathrm{r}_{\mathrm{s}}=-0.31\right)$.

The multivariate results are presented in table 1 . There were increased odds for emphysema (OR 5.5, 95\% CI 1.4-21.0), $\mathrm{CAL}_{\mathrm{GOLD}}\left(\mathrm{OR} 2.8,95 \%\right.$ CI 1.02-7.5) and $\mathrm{CAL}_{\mathrm{LLN}}(\mathrm{OR} 3.1,95 \%$ CI 1.1-8.4) in the highest quartile of B-Cd versus the lowest quartile. The odds ratio for emphysema was still elevated (OR 4.6, 95\% CI 1.3-16.9) in the third B-Cd quartile. In the models, current smoking was associated with emphysema

\begin{tabular}{|c|c|c|c|c|}
\hline Dependent variables (outcomes) & Subjects & $\begin{array}{c}\text { Quartile 2 }^{\#} \\
0.16-<0.23 \mu \mathrm{g} \cdot \mathrm{L}^{-1}\end{array}$ & $\begin{array}{c}\text { Quartile 3 }^{\#} \\
0.23-<0.39 \mu \mathrm{g} \cdot \mathrm{L}^{-1}\end{array}$ & $\begin{array}{c}\text { Quartile } 4^{\#} \\
0.39-3.63 \mu \mathrm{g} \cdot \mathrm{L}^{-}\end{array}$ \\
\hline \multicolumn{5}{|l|}{$\begin{array}{l}\text { Multiple logistic regression } \\
\text { models }\end{array}$} \\
\hline \multicolumn{5}{|l|}{ Model 1} \\
\hline Emphysema & 71 & $1.09(0.2-5.1)$ & $4.6(1.3-16.9)$ & $5.5(1.4-21.0)$ \\
\hline Centrilobular emphysema & 49 & $0.7(0.05-12.0)$ & $8.8(1.1-71.2)$ & $12.4(1.5-102.2$ \\
\hline CAL $G O L D$ & 71 & $2.1(0.8-5.1)$ & $1.7(0.7-4.3)$ & $2.8(1.02-7.5)$ \\
\hline CALLLN & 66 & $1.8(0.7-4.6)$ & $1.7(0.7-4.4)$ & $3.1(1.1-8.4)$ \\
\hline \multicolumn{5}{|l|}{ Model 2} \\
\hline Emphysema & 71 & $1.1(0.2-5.1)$ & $5.3(1.5-19.3)$ & $8.6(2.4-30.8)$ \\
\hline Centrilobular emphysema & 49 & $0.70(0.04-11.7)$ & $9.2(1.1-74.3)$ & $16.0(2.0-127.3$ \\
\hline CAL $G O L D$ & 71 & $2.1(0.8-5.1)$ & $1.7(0.7-4.3)$ & $3.2(1.3-8.1)$ \\
\hline CAL LLN & 66 & $1.8(0.7-4.5)$ & $1.6(0.6-4.2)$ & $3.1(1.2-7.8)$ \\
\hline \multicolumn{5}{|l|}{ Multiple linear regression models } \\
\hline \multicolumn{5}{|l|}{ Model 1} \\
\hline$D_{\mathrm{LcO}} \%$ pred & & 1.5 (NS) & -2.0 (NS) & $-7.4(<0.0001)$ \\
\hline$K_{\mathrm{co}} \%$ pred & & 2.2 (NS) & 3.7 (NS) & -4.0 (NS) \\
\hline TLC \% pred & & 2.4 (NS) & 0.48 (NS) & 0.002 (NS) \\
\hline RV \% pred & & -0.60 (NS) & -0.38 (NS) & -2.6 (NS) \\
\hline \multicolumn{5}{|l|}{ Model 2} \\
\hline$D_{\mathrm{LCO}} \%$ pred & & 1.7 (NS) & -1.8 (NS) & $-7.9(<0.001)$ \\
\hline$K_{\text {co }} \%$ pred & & 2.3 (NS) & 3.8 (NS) & -3.6 (NS) \\
\hline TLC \% pred & & $2.8(<0.05)$ & 1.1 (NS) & 1.3 (NS) \\
\hline RV \% pred & & 0.17 (NS) & 0.73 (NS) & -0.83 (NS) \\
\hline
\end{tabular}

Data are presented as $\mathrm{n}$, odds ratio $(95 \% \mathrm{Cl})$ or estimates ( $\mathrm{p}$-values). The regression models are adjusted for age, former smoking, current smoking, socioeconomic status and occupational exposure. Model 2 adjusted for age, socioeconomic status, occupational exposure and pack-years. CALGOLD: CAL according to Global Initiative for Obstructive Lung Disease; CALLLN: forced expiratory volume in $1 \mathrm{~s} /$ forced vital capacity ratio below the lower limit of normal; $D_{\mathrm{LCO}}$ : diffusing capacity of the lung for carbon monoxide; $K_{\text {co: }}$ transfer coefficient of the lung for carbon monoxide; TLC: total lung capacity; RV: residual volume; NS: nonsignificant. ${ }^{\#}$ : compared with quartile $1\left(<0.16 \mu \mathrm{g} \cdot \mathrm{L}^{-1}\right)$. 
(OR 11.0, 95\% CI 3.9-30.7) and $\mathrm{CAL}_{\mathrm{GOLD}}(\mathrm{OR} 2.8$, 95\% CI 1.2-6.5). When adjusting for cumulative tobacco exposure, the results were similar. Regarding centrilobular emphysema, we found a significantly increased odds ratio in the highest (OR 12.4, 95\% CI 1.5-102.2) as well as in the third B-Cd quartile (OR 8.8, 95\% CI 1.1-71.2). When adjusting for the cumulative tobacco exposure, we found similar results. There was decreased $D_{\mathrm{LCO}}$, but not $K_{\mathrm{CO}}$, in the highest B-Cd quartile compared to the lowest.

The most important findings were the increased prevalence of emphysema in the two upper quartiles of B-Cd (median 0.29 and $0.71 \mu \mathrm{g} \cdot \mathrm{L}^{-1}$ ) compared with the lowest quartile of B-Cd (median $0.13 \mu \mathrm{g} \cdot \mathrm{L}^{-1}$ ). Further supporting the link between emphysema and B-Cd, $D_{\text {LCO }}$ was decreased in the highest B-Cd quartile. The B-Cd levels in the upper quartile are common in many countries, and our results indicate that cadmium at these levels may be an important risk factor for emphysema [13].

The results are in line with previous articles describing increased risk to develop emphysema in workers occupationally exposed to cadmium [2,3]. Rats exposed to cadmium chloride have been reported to develop lesions that resemble centrilobular emphysema [14].

The analyses were adjusted for either smoking categories or cumulative dose of tobacco (pack-years). We consider the cumulative model the most adequate, as the risk of emphysema is more related to the cumulative exposure than to the timing of the exposure (current versus former smoking). However, there is a strong relationship between emphysema and tobacco smoking, and, hence, residual confounding by smoking cannot be excluded.

The main strength of the present study is the use of low-dose CT of the lungs to assess emphysema in combination with lung function. The main limitation of this study is the small sample. Smoking habits were based on self-reported data, and studies have indicated that some ever-smokers may tend to overclassify themselves as never-smokers [15]. If this is the case in our study population, it may mean that a small proportion of never-smokers in the current study indeed may indeed be misclassified smokers.

In conclusion, we suggest that cadmium exposure, in the low dose range, is a risk factor for emphysema. We have controlled for smoking, but there is a need for further general population studies in never-smokers.

Kjell Torén ${ }^{1}$, Anna-Carin Olin ${ }^{1}$, Åse Johnsson ${ }^{2}$, Jenny Vikgren ${ }^{2}$, Niklas Forsgard ${ }^{3}$, Göran Bergström ${ }^{4}$, Gerd Sallsten $^{1}$ and Lars Barregård ${ }^{1}$

${ }^{1}$ Section of Occupational and Environmental Medicine, Dept of Public Health and Community Medicine, Sahlgrenska Academy, University of Gothenburg, Gothenburg, Sweden. ${ }^{2}$ Dept of Radiology, Institute of Clinical Sciences, Sahlgrenska Academy, University of Gothenburg, Gothenburg, Sweden. ${ }^{3}$ Dept of Clinical Chemistry, Sahlgrenska University Hospital, Gothenburg, Sweden. ${ }^{4}$ Dept of Molecular and Clinical Medicine, Institute of Medicine, Sahlgrenska Academy, University of Gothenburg, Gothenburg, Sweden.

Correspondence: Kjell Torén, Section of Occupational and Environmental Medicine, Department of Public Health and Community Medicine, Sahlgrenska Academy, University of Gothenburg, Box 414, S-405 30 Gothenburg, Sweden. E-mail: kjell.toren@amm.gu.se

Received: 18 April 2019| Accepted after revision: 27 July 2019

The study is based on random population sample, which needs a Swedish ethical application to be analysed. The lead author (K. Torén) affirms that the manuscript is an honest, accurate, and transparent account of the study being reported; that no important aspects of the study have been omitted; and that any discrepancies from the study as planned have been explained.

Conflict of interest: K. Torén has nothing to disclose. A-C. Olin has nothing to disclose. A. Johnsson has nothing to disclose. J. Vikgren reports reports personal fees from Boehringer Ingelheim outside the submitted work. N. Forsgard has nothing to disclose. G. Bergström has nothing to disclose. G. Sallsten has nothing to disclose. L. Barregård has nothing to disclose.

Support statement: The main funding body of the Swedish Cardiopulmonary Bioimage Study (SCAPIS) was the Swedish Heart and Lung Foundation. The study was also funded by the Knut and Alice Wallenberg Foundation, the Swedish Research Council (VR), VINNOVA and the Swedish Council for Working Life, Health, and Welfare (FORTE). In addition, there was support from the Sahlgrenska University Hospital, strategic grants from ALF/LUA in Western Sweden and from the Sahlgrenska Academy at University of Gothenburg. Funding information for this article has been deposited with the Crossref Funder Registry.

\section{References}

1 Ganguly K, Levänen B, Palmberg L, et al. Cadmium in tobacco smokers: a neglected link to lung disease. Eur Respir Rev 2018; 27: 170122

2 Friberg L. Health hazards in the manufacture of alkaline accumulators with special reference to chronic cadmium poisoning. Acta Med Scand Suppl 1950; 240: 1-124. 
3 Davison AG, Newman Taylor AJ, Darbyshire J, et al. Cadmium fume inhalation and emphysema. Lancet 1988; i: 663-667.

4 Mannino DM, Holguin F, Greves HM, et al. Urinary cadmium levels predict lower lung function in current and former smokers: data from the Third National Health and Nutrition Examination Survey. Thorax 2004; 59: 194-198.

5 Torén K, Olin A-C, Lindberg A, et al. Vital capacity and COPD: the Swedish CArdioPulmonary BioImage Study (SCAPIS). Int J Chron Obstruct Pulmon Dis 2016; 11: 927-933.

6 MacIntyre N, Crapo RO, Viegi G, et al. Standardisation of the single-breath determination of carbon monoxide uptake in the lung. Eur Respir J 2005; 26: 720-735.

7 Brisman J, Kim J-L, Olin A-C, et al. Spirometric reference equations for Swedish adults. Clin Physiol Funct Imaging 2017; 37: 640-645.

8 Hedenström H, Malmberg P, Agarwal K. Reference values for lung function tests in females. Regression equations with smoking variables. Bull Eur Physiopathol Respir 1985; 21: 551-557.

9 Hedenström H, Malmberg P, Fridriksson HV. Reference values for lung function tests in men: regression equations with smoking variables. Ups J Med Sci 1986; 91: 299-310.

10 Salorinne Y. Single-breath pulmonary diffusing capacity. Reference values and application in connective tissue diseases and in various lung diseases. Scand J Respir Dis Suppl. 1976; 96: 1-84.

11 Barregard L, Sallsten G, Fagerberg B, et al. Blood cadmium levels and incident cardiovascular events during follow-up in a population-based cohort of Swedish adults: the Malmö Diet and Cancer Study. Environ Health Perspect 2016; 124: 594-600.

12 Vikgren J, Khalil M, Cederlund K, et al. Visual and quantitative evaluation of emphysema: a case-control study of 1111 participants in the Pilot Swedish CArdioPulmonary BioImage Study (SCAPIS). Acad Radiol 2019; in press [https://doi.org/10.1016/j.acra.2019.06.019].

13 Tellez-Palza M, Jones MR, Dominguez-Lucas A, et al. Cadmium exposure and clinical cardiovascular disease: a systematic review. Curr Atheroscler Rep 2013; 15: 356.

14 Snider GL, Hayes JA, Korthy AL, et al. Centrilobular emphysema experimentally induced by cadmium aerosol. Am Rev Respir Dis 1973; 108: 40-48.

15 Soulakova JN, Hartmann AM, Liu B, et al. Reliability of adult self-reported smoking history: data from the Tobacco Use Supplement to the Current Population Survey 2002-2003 cohort. Nicotine Tob Res 2012; 14: 952-960 